\title{
A Randomized Trial Testing Deviant Modeling, Peer Gender, and Theft: Replication and Extension
}

Authors :

${\text { Owen Gallupe*a }{ }^{*} \text { Patrick Lalonde }{ }^{\mathrm{a}} \text {, Holly Nguyen }{ }^{\mathrm{b}} \text {, Jennifer Schulenberg }}^{\mathrm{a}}$

Affilitations:

aDepartment of Sociology and Legal Studies

University of Waterloo

${ }^{b}$ Department of Sociology and Criminology

Pennsylvania State University

*Corresponding author address:

ogallupe@uwaterloo.ca

200 University Avenue West

Waterloo, Ontario, Canada

N2L 3G1

519-888-4567 ext. 33361

This is a post-peer-review, pre-copyedit version of an article published in the Journal of Experimental Criminology. The final authenticated version is available online at:

http://dx.doi.org/10.1007/s11292-019-09374-1

This study was funded by Social Sciences and Humanities Research Council of Canada. The authors declare that they have no conflict of interest. 
Author biographies:

Owen Gallupe is an Associate Professor in the Department of Sociology and Legal Studies at the University of Waterloo. His research focuses mainly on peer influence, social networks, and offending. His recent work has been published in venues such as the Journal of Research in Crime and Delinquency, Journal of Quantitative Criminology, and Justice Quarterly.

Patrick Lalonde is a doctoral candidate in the Department of Sociology \& Legal Studies at the University of Waterloo. His research examines borders, security, digitization, governance, and simulation. His work has been published in the British Journal of Criminology and Policing \& Society.

Holly Nguyen is an Assistant Professor in the Department of Sociology and Criminology at the Pennsylvania State University. Her interests include rewards to crime, employment and crime, and criminological theory. Her work has been published in the American Sociological Review, Criminology, and the Journal of Quantitative Criminology.

Jennifer L. Schulenberg is an Associate Professor and Associate Chair in the Department of Sociology and Legal Studies at the University of Waterloo. Her research focuses on evidencebased policing, organizational culture, police discretion, vulnerable populations, youth crime, and research methods. She is the recipient of numerous research grants and awards for outstanding performance, teaching excellence, and the Governor General of Canada Academic Gold Medal. 


\begin{abstract}
Objectives:

Replicate previous experimental findings on the causal effect of deviant peer modeling and assess whether the gender of peer models is an important determinant of theft.
\end{abstract}

Methods:

A randomized control trial ( $n=329$ university students) in which participants were randomly placed into one of four deviant peer modeling groups (control, verbal prompting, behavioral modeling, verbal prompting plus behavioral modeling) and one of three confederate gender similarity groups (same gender, different gender, mixed gender) (4x3 factorial design, equal randomization). The outcome was theft of a gift card. Each session included two confederates and a single participant. This feature reduced measurement error over more common approaches where groups of participants take part in the study at the same time and in which uncontrolled interactions and/or threshold effects may act as confounders.

Results:

Participants were more likely to steal when exposed to confederates who behaviorally modeled theft $(15.1 \%$ stole) or offered verbal support for theft and modeled it $(11.1 \%)$ compared to controls $(2.5 \%)$ or when confederates only talked about stealing $(1.2 \%)(p=.001)$. Participants exposed to same gender peers $(7.3 \%)$ were as likely to steal as those exposed to different gender peers $(5.5 \%)$ or mixed gender peers $(9.9 \%)(p=.464)$.

Conclusions:

Behavioral modeling was found to be an important determinant of theft. This replicated previous research in the area and offers arguably the strongest support to date for the influence of deviant peer modeling. Peer gender, however, was not found to be an important etiological component of theft. External validity is a limitation.

Keywords: social learning theory, gender, modeling, experiment, theft 
As a field of study, criminology is relatively young. We often look to more established fields for inspiration regarding theory and empirics; thus it follows that we ought to also learn from their challenges. One particularly salient challenge is the replicability of seminal findings (Pridemore et al. 2018). As Pridemore et al. (2018: 22) note, criminology is no less prone to reproducibility challenges than other fields; however, it has not been documented to the same extent (though there is some evidence to suggest that it is an impending issue - see McNeely and Warner 2015; other work on the burgeoning replication movement suggests that "the integrity of criminological research looks respectable" - Savolainen and VanEseltine 2018: 241). In an effort to contribute to replicable results, we attempt to reproduce the general findings of a body of recent experimental research showing that modeled deviant behavior impacts individual involvement in deviance, a core tenet of a major criminological theory (social learning theory Akers 2009). To do this, we conducted what we argue to be a more methodologically rigorous randomized control trial than previous studies in this area. However, we also expand on previous research by incorporating methods that allow to us address a topic that has produced mixed findings in the past: the criminogenic impact of the gender composition of the peer group. We proceed by first providing a theoretical and empirical overview of the importance of deviant behavioral modeling; next, the various perspectives on the importance of peer gender are outlined.

\section{Deviant Peer Modeling}

According to Akers (2009: 75), modeling/imitation of offending behavior involves observing the offending of others and acting in a similar way. But despite its theoretical importance and intuitive appeal, evidence for it is comparatively lacking relative to the other elements of social learning theory which have garnered extensive empirical support. As 
pioneered by Akers et al. (1979), attempts to isolate modeling/imitation often involve asking survey respondents to report whether they have witnessed people they admire engaging in deviant acts. While Akers et al. (1979) found some evidence for a modeling effect on alcohol and marijuana use, it was the weakest of the social learning elements (for other examples of this 'admired model' approach, see Kim et al. 2013; Meneses and Akers 2011; Sellers et al. 2005). Overall, a meta-analysis by Pratt et al. (2010) found weak to moderate (but significant) effects on offending of the peer modeling component of peer influence. However, the fact that the estimates of modeling effects in Pratt et al. were based on substantially fewer effect sizes ( $\mathrm{n}=30$ compared to 385 for differential association, 143 for definitions, and 132 for differential reinforcement) speaks to the relative lack of attention given to the modeling element of social learning theory. It is important to note, however, that survey data on peer influence have some well-documented limitations (e.g., Boman et al. 2012). For example, traditional survey studies do not do a good job of distinguishing between genuine peer influences and selection effects (i.e., delinquents being more likely to associate with other delinquents). In fact, Sacerdote (2014) notes that identifying peer effects in the absence of (quasi) experimentation is a difficult task.

Experimental research may be better suited to test modeling/imitation effects than observational research given its ability to isolate peer behavior while holding other theoretically relevant factors such as frequency and intensity of contacts constant. Experimental designs are therefore particularly useful in terms of identifying a causal effect of deviant peer modeling. Bandura et al. $(1961,1963)$ provided an early test of deviant modeling. They showed that participant children who were exposed to aggressive models were more likely than others to imitate aggressive behavior. While their study clearly highlighted a modeling effect, the developmental and status differences between the adult models and the young participant 
children leave open the question of whether these effects would hold when models and imitators were peers. Recent experimental studies addressed peer modeling dynamics in ways that minimize the effect of status differences though there are limitations to this work that necessitates replication before any firm conclusions are drawn.

Experimental Tests of Deviant Modeling

The examples of this body of research most relevant to the focus of our work are reviewed here to highlight the limitations that motivate the current replication. Gino et al. (2009), Paternoster et al. (2013), Mercer et al. (2018), and Gallupe et al. (2016) all conducted experiments on deviant modeling. They all displayed evidence for a peer modeling effect to varying degrees, though uncontrolled variability (measurement error) was an issue in each study. Each of those studies employed a design where a group of university students was brought into a laboratory setting, asked to perform a task, and told that their remuneration depended on their performance. In each study, a confederate modeled a deviant act in front of the group; the outcome was participant commission of the deviant act. Gino et al. (2009), Paternoster et al. (2013), and Gallupe et al. (2016) all showed that exposure to a deviant model increased the probability of participants committing the act. Mercer et al. (2018) found that deviant models did not increase the likelihood of deviance but did increase the amount of it among those who did commit a deviant act. Gino et al. (2009) noted that the deviant modeling effect was contingent upon the in-group versus out-group status of the confederate. Gallupe et al. (2016) isolated the independent and combined effects of verbal prompting and behavioral modeling by having confederates either a) offer verbal support for theft, b) commit theft without any verbal support for it, or c) both offer verbal support for it and actually commit a theft (plus a control group). Furthermore, they varied the number of deviant models (one versus two). They found that none 
of the participants in the control or verbal prompting groups took a gift card compared to $8 \%$ in the behavioral modeling group and $13 \%$ in the verbal plus behavioral modeling group. Their results suggested that actual physical involvement in deviance is the key etiological component; verbal support for deviance is not sufficient though it can exacerbate the effect of behavioral modeling.

While it is difficult to control for all sources of variation beyond the experimental manipulation, the fact that the studies outlined above were all conducted with groups of individuals participating in the experiment at the same time opens up the possibility that both threshold effects and unanticipated interactions among participants may have influenced the likelihood of deviant behavior. Unanticipated interactions may work in either direction: participants may encourage or discourage other participants to engage in deviant behavior in subtle (body language) or overt (direct confrontation) ways beyond the scripted treatments of the confederates. Threshold effects may be relevant if a person is only willing to commit a deviant act if a certain number of others do so (Granovetter 1978; McGloin and Rowan 2015; McGloin and Thomas 2016). In larger groups, witnessing (or suspecting) that a greater number of others have committed the act may result in an unknown proportion of participants also committing the act when they would not have done so in the context of a smaller group. As such, having varying numbers of participants involved in experimental sessions at the same time introduces measurement error.

Another source of measurement error is the fact that, aside from Gallupe et al. (2016), the form of modeling in all of these studies combined verbal prompting with the actual deviant physical behavior (i.e., seeing someone walk out with the ill-gotten gains). Therefore, it is unclear whether the verbal component, the behavioral component, or a combination of both is the 
key mechanism. The results of Gallupe et al. (2016) suggest that actual behavior is the necessary component, but verbal support can strengthen the deviant modeling effect. However, that dynamic has yet to be replicated.

Contrary to common belief, the presence of measurement error does not always attenuate observed effects but can actually inflate estimates for some proportion of studies, particularly those with small samples (as demonstrated by Loken and Gelman 2017). Measurement error, therefore, contributes to problems replicating key findings across studies. With this in mind, we attempted to improve on previous work by minimizing uncontrolled variation by including only a single participant in each session. This allowed us to maintain tighter control over the interactions in the experimental setting and avoided the possibility of differential betweenindividual thresholds moderating the relationship between peer and personal deviance as the number of deviant models was held constant.

One potentially important factor that the aforementioned research neglected was the gender composition of the peer group. Those studies used only male confederates (Gallupe et al. 2016; Gino et al. 2009; Paternoster et al. 2013) or only female confederates (Mercer et al. 2018). A substantial body of literature underscores the idea that gender might be an important determinant of the strength of the deviant peer modeling effect, yet the nature of the effect remains unclear.

\section{Gender and Deviant Modeling}

Years ago, Bandura et al. (1961) found that male children were more likely to imitate adult male models while female children were more likely to imitate adult female models (see also Bussey and Bandura 1984). However, other studies either ignored peer gender or cast doubt on the 'same gender' effect on deviant/offending behavior. For example, Dannick (1973) showed 
that a male model of jaywalking increased the prevalence of jaywalking of both males and females though the effect of a female model was not tested. Russell et al. (1976) observed that males and females were equally able to generate higher levels of jaywalking. Further, Paternoster et al. (2013) and Gallupe et al. (2016) found that male deviant models could spur cheating/theft while Mercer et al. (2018) found that a female deviant model did not increase the likelihood of cheating but did increase the amount of it.

Survey data indicate that there are several ways that the gender composition of deviant peer models might influence offending. Overall however, it is difficult to draw any strong conclusions regarding the criminogenic impact of the gender composition of the peer group, as there are plausible hypotheses that point in opposing directions. As Boman et al. (2014: 175) note, there is a "a surprising lack of knowledge on how the gender structure of dyads or networks impacts peer behavior."

The first set of findings suggest that deviant male models should be more influential to offending than female models for both males and females. According to Haynie et al. (2007: 241), both males and females have an interest in maintaining positive relationships with members of the opposite sex and are therefore open to being influenced by members of the opposite sex. However, given the more pro-social tendencies of girls, their influence tends to be against offending while the greater anti-social tendencies of boys tend to push their influence towards higher levels of delinquent involvement. The work of McCarthy et al. (2004) using a sample of street and school youths broadly support this assertion as does the research on gang members of Peterson et al. (2001) and the ethnographic work on burglars of Decker et al. (1993) and Mullins and Wright (2003). Further, Warr (1996) noted that males were more often instigators of delinquency. However, Weerman and Hoeve (2012) found that the proportion of 
males in the peer group was unrelated to the delinquency of boys or girls in models that accounted for other relevant factors.

A second set of findings suggest that models of the opposite gender are more influential. The implication of these studies tends to be that attempts to impress members of the opposite gender can lead to offending behavior. However, most support for the opposite gender hypothesis comes from the literature on romantic relationships and crime which implies that opposite gender influence might not be the dominant dynamic outside of intimate partner relations. Haynie et al. (2005) found that the deviance of heterosexual romantic partners had an influence on individual deviance (see also Lonardo et al. 2009; Moffit et al. 2002); but while the effect on minor deviance was stronger for females than males (i.e., stronger effect of male partners on females than female partners on males), there was no gender difference for more serious deviance. Dick et al. (2007) is one of the few studies that examined peer group gender composition outside of romantic relationships; they found that having opposite gender friends was related to the alcohol use of both girls and boys. It may be that the desire to impress someone of the opposite gender can lead an individual to offend when the other person models offending behavior.

There are a number of perspectives that lead to the conclusion that same gender peers are risky. These tend to focus either on differences in the content of same gender peer relations or rely on ideas rooted in symbolic interactionism. From the perspective of symbolic interactionism (Blumer 1969; Mead 1934), people attempt to view their behaviors from the standpoint of others ('reflected appraisals' - Matsueda 1992) when assessing the appropriateness of a given course of action. That is, individuals are likely to look to the behavior of the same gender as modeling appropriate behavior. Miller (1958: 14), focusing on the lower socioeconomic strata, similarly 
argued that single-sex peer groups are "the most significant relational unit for both sexes." Haynie et al. (2014: 692-4) summarized the gender-specific dynamics of the 'differential content' perspective by suggesting that females tend to be heavily invested in friendships, embedded in cohesive networks, and are concerned with maintaining relational harmony which leads to a susceptibility to peer influence. For males, displays of normative masculinity often promote deviant behavior as a way to achieve masculinity. While some research supports the idea that same gender peers are risky (e.g., Faris and Felmlee 2011; Maccoby and Wilson 1957), other work displays a complex array of results (Alarid et al. 1996; Gaughan 2006; Li and Guo 2016; Miller 1998; Sanchagrin et al. 2017).

\section{Hypotheses}

Based on previous research, we hypothesize that: a) participants exposed to peers who physically model deviant behavior will be more likely to engage in deviant behavior; b) participants exposed to peers who offer verbal support for deviant behavior without physically engaging in it will be no more likely than controls to engage in deviant behavior though verbal support is expected to enhance the effect of behavioral modeling. Given the variability in past research findings, we do not have specific hypotheses about how peer gender composition will impact deviant involvement, though providing insight into this dynamic is a key objective beyond the replication goals of this study.

\section{Methods}

The primary goal of the current randomized control trial (RCT) was to examine the effect of deviant models on theft, and the role that gender plays in determining this relationship. We closely followed the methods of Gallupe et al. (2016) though we introduced numerous methodological improvements that both allowed for stronger identification of causal effects and 
provided the capacity to isolate the role of peer gender (detailed below). Like them, we recruited a convenience sample of undergraduate students from a Canadian university located in a midsized city. Participants were randomly assigned to either the control group or one of the three experimental treatment groups: 1) a verbal prompting group where the confederates talked about taking a gift card from the table but did not actually do so; 2) a behavioral modeling group where confederates modeled theft without discussing it; 3 ) a verbal prompting plus behavioral modeling group where the confederates both talked about taking a gift card and actually did so. They were also randomly assigned to a group with two female confederates, two male confederates, or one male and one female confederate. This study therefore employed a $4 \times 3$ factorial design (equal randomization). Varying the gender of the confederates improved upon Gallupe et al. (2016) (and others - Gino et al. 2009; Paternoster et al. 2013) which used only male confederates and Mercer et al. (2018) which used only female confederates.

Recruitment was accomplished by widely distributing emails and posters across campus. This was done several times over the course of the study period (October 2015 to June 2016) to generate a sample with sufficient numbers of males and females. In the recruitment material, the study was described as focusing on the relationship between the sight of rewards and task performance. It was also noted that remuneration would be CAN $\$ 20$ in the form of a gift card to a local business. These features were important for creating a realistic scenario in which deviant peer influence could be applied and, given the opportunity, theft was a reasonable course of action. Simple randomization was used to assign participants to treatment groups (using the 'True Random Number Generator' at random.org). Lalonde enrolled and randomly assigned participants after enrollment. While researcher blinding was not employed, this is less of an issue 
when the outcome does not involve an element of subjectivity (Moher et al. 2010: 12) as is the case here where the outcome is whether a participant took a gift card from the table.

We exposed each participant to two confederates acting as deviant models. Gallupe et al. (2016) showed that participants were more likely to engage in theft when it was modeled by two confederates when compared to just one. It is important to maximize the variability in the outcome (theft) to detect an effect as the outcome is a relatively rare event. Exposing all participants to two models of deviant behavior was a way to achieve this. Readers should be cognizant of a potential threshold effect whereby some participants engage in behaviors in response to a certain number of others also committing the act (Granovetter 1978; McGloin and Rowan 2015; McGloin and Thomas 2016). This study ruled out uncontrolled threshold effects by running sessions with only one participant. However, the fact that there were two confederates opens the possibility that some participants who may not have acted in response to a single confederate reached a threshold with a second confederate. Gallupe et al. (2016) showed evidence for a threshold effect in the context of a peer influence experiment in that deviant modeling was more effective with two models compared to one. Thresholds are not something that can be avoided in peer influence experiments and are not inherently problematic. They are, however, a methodological decision. Most research in this vein has chosen to set the threshold at a single deviant peer (Gino et al. 2009; Mercer et al. 2018; Paternoster et al. 2013). This makes sense for relatively common acts such as cheating. But for rarer acts (such as theft), a higher threshold is needed to ensure sufficient variability in the outcome.

Upon arriving in the laboratory, the researcher presented the information and consent forms by showing a video of the principal investigator reading the information form. Participants were told that they would be asked to do a word scramble and that the researchers were 
interested in whether participants who had gift cards placed in front of them would perform better than participants who did not. In fact, the gift cards were placed on the table for all participants (which despite looking authentic had no actual value). They were also told that they would receive fifty cents for each word correctly unscrambled. When the video reached that point, one of the confederates interrupted and said "Wait, I thought we were getting \$20 regardless" to which the researcher (who stopped the video after being interrupted) replied "No, but you can make up to that." The purpose of this exchange was to make the participants feel that they were being cheated as a way to prime them to act on a situation in which theft was possible. Upon completion of the video, participants were asked to sign a consent form if they were still interested in participating. At the end of the study, participants were debriefed and told of the deception and true purpose of the study, informed they would actually receive the full $\$ 20$, and were asked to provide consent again. No participants withdrew consent after being debriefed on the true purpose of the study. Participants spent an average of 35 minutes in the laboratory.

After the initial information and consent process, the researcher placed many gift cards on the table in front of the participant and confederates and stated:

These are the gift cards for the sight of rewards that we are interested in. They are all worth $\$ 20$, but if you don't earn that much, I will get you the right amount in different denominations and change. You have 10 minutes to complete the word scramble. Participants were given exactly 10 minutes to complete the word scramble. The scramble was intentionally very difficult to ensure that participants could not earn the full $\$ 20$ in the allotted time and therefore all would feel somewhat cheated. The average participant correctly unscrambled 10 words (worth $\$ 5$ ) out of a possible 40; the highest scorer unscrambled 30 words (\$15). After 10 minutes, the researcher collected the word scramble sheets and said that he would 
be going to his office to mark them and to get the proper remuneration amount in gift cards and change. In the meantime, participants were asked to complete a questionnaire. It was during the period that the researcher was out of the room (approximately two minutes) that the experimental treatment was applied. In the control group, the confederates did not say anything or take a gift card. They simply filled out the questionnaire. In the verbal prompting group, the confederates talked about taking a gift card from the table but did not actually do so. The following script was used:

Confederate 1: "This sucks. There's no way I did well enough to make \$20."

Confederate 2: "Ya, this is bullshit. We were definitely promised $\$ 20$."

Confederate 1: “I wouldn’t have come if I knew I was only getting like \$5.”

Confederate 2: (Pointing at the cards) "Fuck it. We should all grab one."

In the behavioral modeling group, the confederates both took a gift card from the table without talking about it. Confederate 1 said "Ok" simply to draw attention to the fact that they were taking a gift card. Confederate 2 gave a quick laugh and then also took one. In the verbal prompting plus behavioral modeling group, the confederates both talked about taking a gift card and actually did so. The above script was employed but with the following added to the end as previous work found that ending it at the same spot appeared awkward:

Confederate 1: "And get ratted out?"

Confederate 2: "Who's going to say anything?"

Confederate 1: "True. I'm in if you are."

Confederate 2: "Done."

After debriefing, participants were asked a series of follow-up questions that addressed the believability of the study. On a scale from 1 (not at all believable) to 10 (highly believable), 
$93 \%$ rated the believability of the study to be 5 or higher (mean=7.9, median=8) and $93 \%$ also rated the believability of the confederates at a 5 or above (mean=8.4, median=9). Additionally, no participants reported being aware of the true nature of the study in advance which suggests that participants were not contaminated by talking to others who had previously taken part.

A total of 335 students participated, though a small number opted out after being told that their pay depended upon their performance on the task or reported that they did not identify as male or female and were omitted from analyses to avoid the risk of deductive disclosure. The analytic sample was therefore 329 participants. Sample size was based on a power analysis which suggested that 27 participants were needed in each of the 12 groups to achieve a power of 0.8 at an alpha of .01 and a delta of 0.62 (calculated using conservative parameters) (average group size $=27.4$ participants). The trial ended once the necessary sample size was achieved. The fact that only one participant was included in each session (along with two confederates) was a substantial improvement over previous studies. It strengthened researcher control over the social environment by minimizing any unpredictable social interactions that may have influenced the likelihood of theft in unknown ways and therefore effectively ruled out uncontrolled interactions as a potential source of variation. Having greater control over the laboratory environment also ensured that treatment dilution (Angrist 2006; Gartin 1995) was not an issue like it was in Gallupe et al. (2016). All participants received the experimental treatment of the group into which they were randomized.

The use of confederates as deviant models meant that participants and models were strangers which rendered this a conservative test of modeling/imitation. While Sutherland (1947) (and subsequently Akers 2009) argued that intensity of associations is an important modality of the influence process, this does not rule out the possibility that people can be affected by those 
with whom they have no relationship. This is evident in Akers' (2009) discussion of the influence of media (76) and reference to concepts such as 'vicarious reinforcement' (58). By taking the approach that we did, we effectively held intensity constant. In fact, all four of Sutherland's (1947) modalities (intensity, duration, frequency, priority) were held constant (i.e., there was no variation). Sutherland argued that interpersonal connections can range from highly intense relationships that were established early in life, persist over a long period, and involve frequent contact to exposure to strangers a single time. The current experiment creates a situation where deviant peer exposure is uniformly of little intensity, brief duration ( $\sim 30$ minutes), a onetime contact, and established in adulthood. It is therefore not a test of Sutherland's four modalities. It is, however, directed at one of the four core elements outlined by Akers (2009) (modeling/imitation). As such, this is a test that is more closely aligned with Akers' social learning theory than it is Sutherland's differential association theory. ${ }^{1}$

The expansion to account for gendered peer dynamics does not undermine the replication goal directed at deviant modeling since it requires only systematic variation in the gender of the confederates, not their actions. As Pridemore et al. (2018: 22) note, "if a minor alteration in method leads to very different results...then the original finding is unstable." We do not expect support for the core hypothesis surrounding the importance of behavioral modeling to change a great deal based on peer gender variation, but it is of theoretical interest to assess whether the strength of the modeling effect systematically varies based on peer gender. In other words, we expect that peer modeling increases the probability of theft regardless of peer gender, but the effect might be somewhat stronger or weaker depending on whether peers are same gender, different gender, or a combination. 
Randomization appears to have been successful. As shown in table 1, similar percentages experienced each experimental group (25-26\%) and confederate gender combination (33-34\%). Cross-tabulating these two variables showed that all cell percentages were between $6.4 \%$ and $10.0 \%$; a chi-square test revealed that the differences in these cell percentages were not significant ( $p=.591$ - results available on request). Table 2 shows that there were no systematic demographic differences across the experimental treatment groups or across confederate gender composition groups.

\section{INSERT TABLE 1 HERE}

\section{INSERT TABLE 2 HERE}

The dataset generated and analyzed during the current study is available in the openICPSR repository (Gallupe et al. 2019).

Compliance with Ethical Standards

All procedures performed in studies involving human participants were in accordance with the ethical standards of the institutional research committee. Informed consent was obtained from all individual participants included in the study. The authors declare that they have no conflict of interest. No adverse events were reported.

Results

Peer Modeling and Theft

Table 3 shows that there were significant differences between the modeling groups in the likelihood of theft $(p=.001)$. Very few participants in the control $(2.5 \%)$ and verbal prompting groups (1.2\%) took a gift card (see online supplementary material for tables of risk differences). However, a substantial percentage of participants in the behavioral modeling $(15.1 \%)$ and verbal plus behavioral modeling groups $(11.1 \%)$ stole a card. While verbal prompting on its own did 
not appear to cause others to commit theft, participants were clearly more responsive to the confederates when they actually took a card themselves. However, unlike the results of Gallupe et al. (2016), verbal prompting did not appear to add anything to the effect of behavioral modeling. ${ }^{2}$ These results offered support for previous research showing that the deviant behavior of peers has a causal impact on individual offending (e.g., Gallupe et al. 2016; Paternoster et al. 2013). We now turn to an examination of gendered peer effects on individual deviance.

\section{INSERT TABLE 3 HERE}

Confederate Gender and Theft

Eight percent of males $(n=11)$ committed theft compared to $7 \%$ of females $(n=14$, $p=.803$ ). There were no significant differences in the likelihood of theft across the different gender similarity groups (table 3). While there were more thefts when there was one female and one male confederate $(9.9 \%)$ than when the confederates were the same gender as the participants $(7.3 \%)$ or when the confederates were a different gender from the participants $(5.5 \%)$, these differences were not significant $(p=.464)$. We also examined this in a slightly different way; that is, by shifting the focus from confederate gender similarity to confederate gender (i.e., two female confederates, two male confederates, one male and one female confederate). This did not alter the results (no significant group differences) $(p=.303){ }^{3}$

There is suggestive evidence of an interaction between modeling group and confederate gender similarity $(p=.003)$ though there is little in the way of a discernible pattern to these results (table 4). The two groups with the highest percentage of thefts were the behavioral modeling with same gender peers group (26.1\% of participants committed theft) and the verbal prompting plus behavioral modeling with mixed gender peers group $(20.8 \%)$. While the interaction was statistically significant, we recommend caution in interpreting these results given the smaller 
number of cases per group relative to the main (non-interaction) analysis. While the sample size was based on an a priori power analysis using conservative estimates of expected effect sizes from Gallupe et al. (2016) which showed that there should be 27 cases per group (actual average group size $=27.4$ participants) to achieve an expected power of 0.8 at an alpha of .01 and a delta of 0.62 , this finding would benefit from replication before considering it to be conclusive. ${ }^{4}$ Overall, the most sensible interpretation is that deviant modeling has important behavioral consequences that operates regardless of peer gender similarity. Importantly, by randomly assigning participants to groups with varying confederate gender combinations, we have ensured that any effects of peer modeling are not attributable to peer gender dynamics. As such, it strengthens interpretations of a causal modeling effect by ruling out peer gender as a potential confounder.

\section{INSERT TABLE 4 HERE}

\section{Discussion}

In this study, we attempted to replicate the results of previous experimental research showing a causal effect of deviant peer modeling on theft using what we argue to be a more methodologically rigorous approach. In doing so, we employed methods that allowed us to test whether gender similarity with deviant models has an impact on the likelihood of committing theft. Using a randomized control trial, we found that being exposed to others who model theft increased the likelihood of stealing. These results showed that people who witnessed others physically take a gift card from the table in front of them were more likely to also take a card than the control group or those who were only exposed to verbal support for theft. This can be considered a successful replication of previous work displaying the behavioral importance of peer modeling (Gallupe et al. 2016; Gino et al. 2009; Paternoster et al. 2013). The fact that these 
results hold when minimizing the potential for measurement error provides the strongest evidence to date that deviant peer modeling is in fact causally related to offending. Our approach to reducing measurement error revolved around three adjustments to previous work: 1) the effect of verbal prompting was separated from behavioral modeling (this followed Gallupe et al. 2016 but extends beyond most other relevant research); 2) experimental sessions were conducted with a single participant and therefore strong control over potential confounding interactions was exerted; 3) peer gender dynamics were accounted for by randomly assigning participants to same gender, different gender, or mixed gender groups. Given that the effects of peer modeling continues to hold speaks to its increasingly secure place as a key etiological component of offending.

The fact that the peer modelers were not close ties to the participants suggests that the current experiment is likely to be a conservative test of deviant peer modeling. Previous work has argued that people are more likely to comply with attempts to influence when carried out by highly valued others (e.g., Blau 1964; Giordano et al. 2006). In fact, the importance of close interpersonal ties was addressed by Sutherland (1947) who stated that social learning mainly occurs in intimate groups and emphasized the importance of frequency, duration, priority, and intensity of contacts, all factors that exert a stronger influence when relational ties are close. Our results highlight the fact that the transmission of 'definitions' conducive to offending (Sutherland 1947) can occur even among peers that are not emotionally bonded. However, it is likely that modeling would be found to exert an even stronger effect when the modeler is someone whose opinion carries substantial weight to the individual.

Peer group gender composition was not found to be related to theft. The results did not show any statistically significant differences in the likelihood of theft between those exposed to 
same gender peers, different gender peers, or a mixture of both. Viewed in an alternative way, male models of deviant behavior were no more or less influential than female models or a combination of males and females. These findings contradict the classic research of Bandura (Bandura et al. 1961; Bussey and Bandura 1984) showing a same gender modeling effect. However, there were clear developmental differences between the adult model and the child participants in that work which appear to be important in determining the likelihood of following modeled behavior. When those developmental differences are essentially eliminated as was the case in the current study that used (mostly young) adult participants and confederates, the peer gender effect disappeared. This is more in line with such research as the jaywalking study by Russell et al. (1976) in which males and females were similar in their capacity to spur jaywalking by others.

From a theoretical perspective, this work also does not offer much support for a symbolic interactionist perspective on the importance of peer gender. From this perspective, individuals attempt to view themselves from the perspective of others when contemplating an appropriate course of action (e.g., Blumer 1969; Matsueda 1992). Peer gender might be important in that, when attempting to take the viewpoint of others, the likelihood of perceiving a particular modeled course of action as appropriate is easier when the modeler is of the same gender. However, we found no support for this perspective. We also found no support for the crossgender influence dynamic suggested by research on deviant similarity across heterosexual romantic partnerships (e.g., Haynie et al. 2005). This is not entirely surprising given that the deviant models and participants were not romantically involved. One implication of this finding is that previous studies on the causal impact of deviant modeling (e.g., Gallupe et al. 2016; 
Paternoster et al. 2013) were not likely hampered by their use of deviant models of one gender only.

An additional avenue for future research relates to the verbal component of deviant peer influence. In the present study, the dialogue in the two groups that contained a verbal component was directed between the two confederates. This was done to ensure that there was no direct verbal pressure placed on the participants which would have confounded the effect of peer modeling that is only witnessed. However, it would be useful for future work to extend the current study by having confederates directly address participants and exert varying amounts of verbal pressure to engage in offending behavior. It is likely that witnessing people talk amongst themselves has a different criminogenic effect than a direct verbal interaction with someone attempting to persuade them to commit a deviant act, something that previous research has indicated can promote unethical behavior (e.g., Bohns et al. 2014).

Limitations

It should be noted that certain elements of the experimental treatment can be viewed as reinforcement rather than modeling. In particular, the quick laugh of the confederate in the behavioral modeling group and the "I'm in if you are" line in the verbal prompting plus behavioral modeling group may have sent the message that theft would elicit a socially rewarding response. These components were included in the experimental treatment to boost believability (to make the treatments seem more natural) but at the expense of adding in what we see as a mild confounding element. We feel that it is impossible to have confederates model a behavior without implicitly sending the message that it will be viewed positively. Thus, while we argue that modeling rather than reinforcement is the true causal mechanism in this study, the role 
of reinforcement cannot be ruled out. This leaves open a contribution for future work to disentangle.

To reiterate a point made earlier, deviant peer models were not close ties and peers exhibited no variation in Sutherland's (1947) four modalities that condition the peer influence effect (intensity, duration, priority, frequency). As such, this experiment was not a strong test of Sutherland's differential association theory. Nor was it a complete test of Akers' (2009) social learning theory; instead it was a focused test of the modeling/imitation component, something that is particularly amenable to experimental manipulation.

Crafting a complete experimental test of social learning theory with human participants would appear to be an extremely difficult task since there are many mechanisms to incorporate. However, survey experimental methods using vignettes (e.g., McGloin and Thomas 2016) could be used to target many aspects of the theory while leveraging the large sample sizes that can be achieved using surveys. By posing situations that randomize such phrasing as "you are hanging out with your best friend/a good friend/a friend/an acquaintance when they [commit X act]...," you could isolate elements such as intensity. A similar thing could be done with priority ("someone you have known since you were $2 / 3 / 4 / 5$, etc. years old"), duration ("someone you have known for less than a year/a year/2 years/3 years, etc."), and frequency ("someone you hardly ever see/.../see most days"). Vignette methods could also be used to experimentally manipulate the extent to which certain behaviors are reinforced ("when you [committed X act], your friends thought it was hilarious/.../got really mad at you"). While this approach would allow for much fuller experimental tests of the theory, there would, for at least some people, be a disjuncture between what they say they would do and what they would actually do. Though some research suggests that this problem might be overblown since intentions tend to be related to 
action (Kim and Hunter 1993; Sheppard et al. 1988; but see Exum and Layana 2018), the problem is entirely avoided in the current study since actions were directly observed. Regardless, extending on the current line of experimental tests of peer influence in ways that get at underlying (and under researched) mechanisms is a way to push the field in a productive direction (McGloin and Thomas 2019).

There is still a place for in-person peer influence experiments that go beyond simply whether or not peer influence exists. For example, responsivity to peer modeling that varies by the race, age, perceived socioeconomic status, etc. of the modeler would help establish the boundaries of the deviant modeling effect.

A further limitation is the age of the sample. The average age of 20.6 places this sample on the back end of the age-crime curve meaning that, everything else being equal, the sample is not as crime-prone as a sample of 16-17 year olds. Furthermore, the sample consists of people at an age when gender mixing is the norm. As such, the gender of peers may make little difference to offending at this age since most people associate with both males and females; peer behavior may still be important but there appears to be little distinction made between male peer behavior and female peer behavior when it comes to a relatively gender-neutral behavior such as theft. It is possible that a stronger correlation to gendered peer influence would be found in an early adolescent sample since it is an age when gender mixing is much less common. As Dick et al. (2007: 2017) speculate, cross-gender interactions in early adolescence could reflect greater disinhibition and sensation-seeking, characteristics associated with higher levels of delinquency. In all, the adult sample is likely to have been a conservative test of gendered peer influence. While our work shows no peer gender effect, replications with different age groups are needed before reaching any firm conclusions on the role of peer gender. 
External validity is a major limitation of any laboratory-based experimental study and ours is no exception. A laboratory is not a 'natural habitat' which calls into question how people would react to peer modeling in other environments. Mitigating this concern somewhat is the fact that while the study took place in a laboratory, the scenario was experienced by participants as very realistic (mean believability rating $=7.90$ out of 10 ). The high level of realism was achieved by employing deceptive methods (for which extensive debriefing was conducted). This suggests that the study has a reasonable degree of external validity as it mimicked a scenario that could be experienced in similar form outside of the laboratory environment. However, the extent to which the results can be generalized beyond an undergraduate sample or to peer modeling and peer gender dynamics associated with other behaviors (e.g., violence) is unclear. Replication using representative samples or samples recruited in public areas would elicit more social class diversity among respondents and help to strengthen inferences. Despite the limitations, our study offers strong support for previous experimental research in this area. Overall, the results indicated that the behavioral modeling of theft was causally related to individual theft. The gender composition of the peer group, however, was not found to influence theft. 


\section{Notes}

${ }^{1}$ We credit an anonymous reviewer for this point.

${ }^{2} \mathrm{~A}$ number of sensitivity analyses were conducted to assess whether the results were dependent on the type of test conducted. Following Paternoster et al. (2013), we also estimated a linear probability model. The results did not change the interpretation in any way. Additionally, we controlled for the number of words correctly unscrambled, a proxy for motivation (i.e., students who unscrambled fewer words would be under the impression that they would be earning less); it was not related to theft and did not alter other effects.

${ }^{3}$ As with the peer modeling analysis, we supplemented the gender similarity analysis with linear probability models and also controlled for the number of words unscrambled using a logistic regression model. The results were unaltered.

${ }^{4}$ We further probed this effect through a number of sensitivity analyses. We estimated both linear probability and Firth logit models (due to zero counts in some cells of the interaction - see Firth 1993 and Heinze and Schemper 2002) predicting theft from the interaction between peer modeling and gender similarity; the interaction term was not significant in either type of model. 


\section{Acknowledgements}

This research was supported by the Social Sciences and Humanities Research Council of Canada. The authors would like to thank Kirran Iveson, Jeremiah Johnson, Krisha Ruchlewicz, and Ashley Ryan for their research assistance and Dana Haynie for her comments on an earlier version. 


\section{References}

Akers, R. L. (2009). Social learning and social structure: A general theory of crime and deviance. New Brunswick, N.J.: Transaction.

Akers, R. L., Krohn, M. D., Lanza-Kaduce, L., \& Radosevich, M. (1979). Social learning and deviant behavior: A specific test of a general theory. American Sociological Review, 44(4), 636-655.

Alarid, L. F., Marquart, J. W., Burton, V. S., Cullen, F. T., \& Cuvelier, S. J. (1996). Women's roles in serious offenses: A study of adult felons. Justice Quarterly, 13(3), 431-454. https://doi.org/10.1080/07418829600093041

Angrist, J. D. (2006). Instrumental variables methods in experimental criminological research: What, why and how. Journal of Experimental Criminology, 2(1), 23-44. https://doi.org/10.1007/s11292-005-5126-X

Bandura, A., Ross, D., \& Ross, S. A. (1961). Transmission of aggression through imitation of aggressive models. Journal of Abnormal and Social Psychology, 63(3), 575-582. https://doi.org/10.1037/h0045925

Bandura, A., Ross, D., \& Ross, S. A. (1963). Vicarious reinforcement and imitative learning. Journal of Abnormal and Social Psychology, 67(6), 601-607. https://doi.org/10.1037/h0045550

Blau, P. M. (1964). Exchange and power in social life. New York: Wiley.

Blumer, H. (1969). Symbolic interactionism: Perspective and method. Englewood Cliffs, N.J.: Prentice-Hall. 
Bohns, V. K., Roghanizad, M. M., \& Xu, A. Z. (2014). Underestimating our influence over others' unethical behavior and decisions. Personality and Social Psychology Bulletin, 4O(3), 348-362. https://doi.org/10.1177/0146167213511825

Boman, J. H., IV, Miller, B. L., Stogner, J., Agnich, L. E., \& Krohn, M. D. (2014). Examining perceptions of peer substance use in friendships of different gender structure. Journal of Crime and Justice, 37(2), 173-196. https://doi.org/10.1080/0735648X.2013.777210

Boman, J. H., IV, Stogner, J. M., Miller, B. L., Griffin, O. H., III, \& Krohn, M. D. (2012). On the operational validity of perceptual peer delinquency: Exploring projection and elements contained in perceptions. Journal of Research in Crime and Delinquency, 49(4), 601621. https://doi.org/10.1177/0022427811419367

Bussey, K., \& Bandura, A. (1984). Influence of gender constancy and social power on sex-linked modeling. Journal of Personality and Social Psychology, 47(6), 1292-1302. https://doi.org/10.1037/0022-3514.47.6.1292

Dannick, L. I. (1973). Influence of an anonymous stranger on a routine decision to act or not to act: An experiment in conformity. The Sociological Quarterly, 14(1), 127-134.

Decker, S., Wright, R., Redfern, A., \& Smith, D. (1993). A woman's place is in the home: Females and residential burglary. Justice Quarterly, 10(1), 143-162. https://doi.org/10.1080/07418829300091741

Dick, D. M., Pagan, J. L., Holliday, C., Viken, R., Pulkkinen, L., Kaprio, J., \& Rose, R. J. (2007). Gender differences in friends' influences on adolescent drinking: A genetic epidemiological study. Alcoholism: Clinical and Experimental Research, 31(12), 20122019. http://doi.org/10.1111/j.1530-0277.2007.00523.x 
Exum, M. L., \& Layana, M. C. (2018). A test of the predictive validity of hypothetical intentions to offend. Journal of Crime and Justice, 41(2), 136-154.

https://doi.org/10.1080/0735648X.2016.1244486

Faris, R., \& Felmlee, D. (2011). Status struggles: Network centrality and gender segregation in same- and cross-gender aggression. American Sociological Review, 76(1), 48-73. https://doi.org/10.1177/0003122410396196

Firth, D. (1993). Bias reduction of maximum likelihood estimates. Biometrika, 80(1), 27-38.

Gallupe, O., Lalonde, P., Nguyen, H., \& Schulenberg, J. (2019). Peer influence and theft [data set]. Ann Arbor, MI: Inter-university Consortium for Political and Social Research [distributor]. https://doi.org/10.3886/E104581V

Gallupe, O., Nguyen, H., Bouchard, M., Schulenberg, J. L., Chenier, A., \& Cook, K. D. (2016). An experimental test of deviant modeling. Journal of Research in Crime and Delinquency, 53(4), 482-505. https://doi.org/10.1177/0022427815625093

Gartin, P. R. (1995). Dealing with design failures in randomized field experiments: Analytic issues regarding the evaluation of treatment effects. Journal of Research in Crime and Delinquency, 32(4), 425-445. https://doi.org/10.1177/0022427895032004003

Gaughan, M. (2006). The gender structure of adolescent peer influence on drinking. Journal of Health and Social Behavior, 47(1), 47-61. https://doi.org/10.1177/002214650604700104

Gino, F., Ayal, S., \& Ariely, D. (2009). Contagion and differentiation in unethical behavior: The effect of one bad apple on the barrel. Psychological Science, 20(3), 393-398. https://doi.org/10.1111/j.1467-9280.2009.02306.x 
Giordano, P. C., Longmore, M. A., \& Manning, W. D. (2006). Gender and the meanings of adolescent romantic relationships: A focus on boys. American Sociological Review, 71(2), 260-287. https://doi.org/10.1177/000312240607100205

Granovetter, M. (1978). Threshold models of collective behavior. American Journal of Sociology, 83(6), 1420-1443. https://doi.org/10.2307/2778111

Haynie, D. L., Doogan, N. J., \& Soller, B. (2014). Gender, friendship networks, and delinquency: A dynamic network approach. Criminology, 52(4), 688-722. https://doi.org/10.1111/1745-9125.12052

Haynie, D. L., Giordano, P. C., Manning, W. D., \& Longmore, M. A. (2005). Adolescent romantic relationships and delinquency involvement. Criminology, 43(1), 177-210. https://doi.org/10.1111/j.0011-1348.2005.00006.x

Haynie, D. L., Steffensmeier, D., \& Bell, K. E. (2007). Gender and serious violence: Untangling the role of friendship sex composition and peer violence. Youth Violence and Juvenile Justice, 5(3), 235-253. https://doi.org/10.1177/1541204007300358

Heinze, G., \& Schemper, M. (2002). A solution to the problem of separation in logistic regression. Statistics in Medicine, 21(16), 2409-2419. https://doi.org/10.1002/sim.1047

Kim, E., Akers, R. L., \& Yun, M. (2013). A cross-cultural test of social structure and social learning: Alcohol use among South Korean adolescents. Deviant Behavior, 34(11), 895915. https://doi.org/10.1080/01639625.2013.782787

Kim, M.-S., \& Hunter, J. E. (1993). Relationships among attitudes, behavioral intentions, and behavior: A meta-analysis of past research, part 2. Communication Research, 20(3), 331364. https://doi.org/10.1177/009365093020003001 
Li, Y., \& Guo, G. (2016). Peer influence on aggressive behavior, smoking, and sexual behavior: A study of randomly-assigned college roommates. Journal of Health and Social Behavior, 57(3), 297-318. https://doi.org/10.1177/0022146516661594

Loken, E., \& Gelman, A. (2017). Measurement error and the replication crisis. Science, 355(6325), 584-585. https://doi.org/10.1126/science.aal3618

Lonardo, R. A., Giordano, P. C., Longmore, M. A., \& Manning, W. D. (2009). Parents, friends, and romantic partners: Enmeshment in deviant networks and adolescent delinquency involvement. Journal of Youth and Adolescence, 38(3), 367-383. https://doi.org/10.1007/s10964-008-9333-4

Maccoby, E. E., \& Wilson, W. C. (1957). Identification and observational learning from films. The Journal of Abnormal and Social Psychology, 55(1), 76-87. https://doi.org/10.1037/h0043015

Matsueda, R. L. (1992). Reflected appraisals, parental labeling, and delinquency: Specifying a symbolic interactionist theory. American Journal of Sociology, 97(6), 1577-1611.

McCarthy, B., Felmlee, D., \& Hagan, J. (2004). Girl friends are better: Gender, friends, and crime among school and street youth. Criminology, 42(4), 805-835. https://doi.org/10.1111/j.1745-9125.2004.tb00537.x

McGloin, J. M., \& Rowan, Z. R. (2015). A threshold model of collective crime. Criminology, 53(3), 484-512. https://doi.org/10.1111/1745-9125.12077

McGloin, J. M., \& Thomas, K. J. (2016). Incentives for collective deviance: Group size and changes in perceived risk, cost, and reward. Criminology, 54(3), 459-486. https://doi.org/10.1111/1745-9125.12111 
McGloin, J. M., \& Thomas, K. J. (2019). Peer influence and delinquency. Annual Review of Criminology, 2, 241-264. https://doi.org/10.1146/annurev-criminol-011518-024551

McNeeley, S., \& Warner, J. J. (2015). Replication in criminology: A necessary practice. European Journal of Criminology, 12(5), 581-597. https://doi.org/10.1177/1477370815578197

Mead, G. H. (1934). Mind, Self and Society. Chicago, IL: University of Chicago.

Meneses, R. A., \& Akers, R. L. (2011). A comparison of four general theories of crime and deviance: Marijuana use among American and Bolivian university students. International Criminal Justice Review, 21(4), 333-352. https://doi.org/10.1177/1057567711408302

Mercer, N., Crocetti, E., Meeus, W., \& Branje, S. (2018). An experimental investigation of the influence of deviant peers on own deviancy: A replication study. Journal of Experimental Criminology, 14(3), 429-438. https://doi.org/10.1007/s11292-017-9305-3

Miller, J. (1998). Up it up: Gender and the accomplishment of street robbery. Criminology, 36(1), 37-66. https://doi.org/10.1111/j.1745-9125.1998.tb01239.x

Miller, W. B. (1958). Lower class culture as a generating milieu of gang delinquency. Journal of Social Issues, 14(3), 5-19. https://doi.org/10.1111/j.1540-4560.1958.tb01413.x

Moffitt, T. E., Caspi, A., Rutter, M., \& Silva, P. A. (2002). Sex differences in antisocial behavior: Conduct disorder, delinquency, and violence in the Dunedin Longitudinal Study. Cambridge: Cambridge University Press.

Moher, D., Hopewell, S., Schulz, K. F., Montori, V., Gøtzsche, P. C., Devereaux, P. J., Elbourne, D., Egger, M., \& Altman, D. G. (2010). CONSORT 2010 explanation and elaboration: updated guidelines for reporting parallel group randomised trials. BMJ, 340, c869. https://doi.org/10.1136/bmj.c869 
Mullins, C. W., \& Wright, R. (2003). Gender, social networks, and residential burglary. Criminology, 41(3), 813-840. https://doi.org/10.1111/j.1745-9125.2003.tb01005.x

Paternoster, R., McGloin, J. M., Nguyen, H., \& Thomas, K. J. (2013). The causal impact of exposure to deviant peers: An experimental investigation. Journal of Research in Crime and Delinquency, 50(4), 476-503. https://doi.org/10.1177/0022427812444274

Peterson, D., Miller, J., \& Esbensen, F.-A. (2001). The impact of sex composition on gangs and gang member delinquency. Criminology, 39(2), 411-440. https://doi.org/10.1111/j.17459125.2001.tb00928.x

Pratt, T. C., Cullen, F. T., Sellers, C. S., Winfree, L. T., Jr., Madensen, T. D., Daigle, L. E., ... Gau, J. M. (2010). The empirical status of social learning theory: A meta-analysis. Justice Quarterly, 27(6), 765-802. https://doi.org/10.1080/07418820903379610

Pridemore, W. A., Makel, M. C., \& Plucker, J. A. (2018). Replication in criminology and the social sciences. Annual Review of Criminology 1:19-38. https://doi.org/10.1146/annurevcriminol-032317-091849

Russell, J. C., Wilson, D. O., \& Jenkins, J. F. (1976). Informational properties of jaywalking models as determinants of imitated jaywalking: An extension to model sex, race and number. Sociometry, 39(3), 270-273. https://doi.org/10.2307/2786520

Sacerdote, B. (2014). Experimental and quasi-experimental analysis of peer effects: Two steps forward? Annual Review of Economics, 6(1), 253-272. https://doi.org/10.1146/annureveconomics-071813-104217

Sanchagrin, K., Heimer, K., \& Paik, A. (2017). Adolescent delinquency, drinking, and smoking: Does the gender of friends matter? Youth \& Society, 49(6), 805-826. https://doi.org/10.1177/0044118x14563050 
Savolainen, J., \& VanEseltine, M. (2018). Replication and research integrity in criminology: Introduction to the special issue. Journal of Contemporary Criminal Justice, 34(3), 236244. https://doi.org/10.1177/1043986218777288

Sellers, C. S., Cochran, J. K., \& Branch, K. A. (2005). Social learning theory and partner violence: A research note. Deviant Behavior, 26(4), 379-395. https://doi.org/10.1080/016396290931669

Sheppard, B. H., Hartwick, J., \& Warshaw, P. R. (1988). The theory of reasoned action: A metaanalysis of past research with recommendations for modifications and future research. Journal of Consumer Research, 15(3), 325-343. https://doi.org/10.1086/209170

Sutherland, E. H. (1947). Principles of criminology (Vol. 4). Philadelphia: J. B. Lippincott.

Warr, M. (1996). Organization and instigation in delinquent groups. Criminology, 34(1), 11-37. https://doi.org/10.1111/j.1745-9125.1996.tb01193.x

Weerman, F. M., \& Hoeve, M. (2012). Peers and delinquency among girls and boys: Are sex differences in delinquency explained by peer factors? European Journal of Criminology, 9(3), 228-244. https://doi.org/10.1177/1477370811435736 
Table 1. Participants per group $-\mathrm{n}(\%)$

\begin{tabular}{lrlr}
\hline \multicolumn{2}{c}{ Modeling group } & \multicolumn{2}{c}{ Gender similarity group } \\
\hline Control & $81(24.6)$ & Same $^{\mathrm{b}}$ & $109(33.1)$ \\
Verbal prompting & $81(24.6)$ & Different $^{\mathrm{c}}$ & $109(33.1)$ \\
Behavioral modeling & $86(26.1)$ & Mixed $^{\mathrm{d}}$ & $111(33.7)$ \\
Verbal + behavioral $^{\mathrm{a}}$ & $81(24.6)$ & & \\
Total & $329(100)$ & & $329(100)$ \\
\hline
\end{tabular}

${ }^{\text {a }}$ Verbal prompting plus behavioral modeling group.

bParticipant and confederates same gender.

'Participant and confederates different gender.

${ }^{\mathrm{d}}$ Mixed gender (both male and female confederates). 
Table 2. Descriptive Statistics

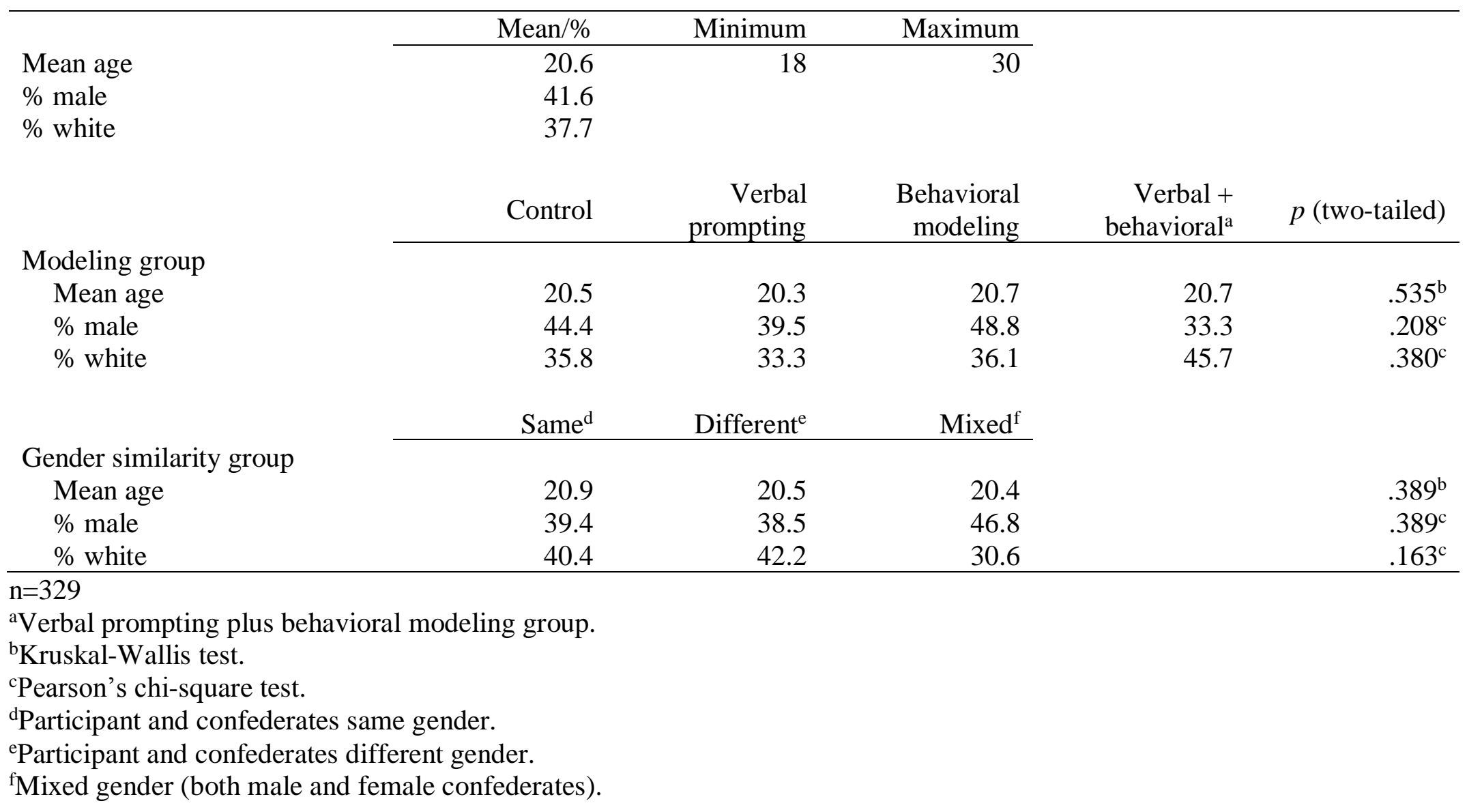


Table 3. Thefts per group $-\mathrm{n}(\%)$

\begin{tabular}{|c|c|c|c|}
\hline \multicolumn{2}{|c|}{ Modeling group } & \multicolumn{2}{|c|}{ Gender similarity group } \\
\hline Control & $2(2.5)$ & Same $^{\mathrm{a}}$ & $8(7.3)$ \\
\hline Verbal prompting & $1(1.2)$ & Different ${ }^{b}$ & $6(5.5)$ \\
\hline Behavioral modeling & $13(15.1)$ & Mixed $^{\mathrm{c}}$ & $11(9.9)$ \\
\hline 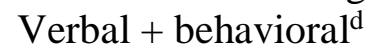 & $9(11.1)$ & & \\
\hline Total & $25(7.6)$ & & $25(7.6)$ \\
\hline$p^{\mathrm{e}}$ (two-tailed) & .001 & & .464 \\
\hline 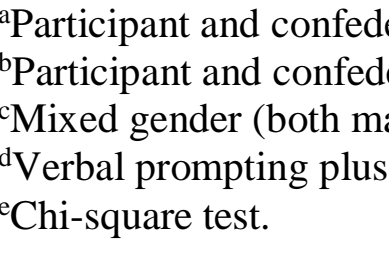 & $\begin{array}{l}\text { tes same ge } \\
\text { tes differen } \\
\text { and female } \\
\text { havioral } \mathrm{mc}\end{array}$ & $\begin{array}{l}\text { r. } \\
\text { nder. } \\
\text { hfederates). } \\
\text { ing group. }\end{array}$ & \\
\hline
\end{tabular}


Table 4. Thefts per group: Interaction between peer modeling and gender similarity $-\mathrm{n}(\%)$

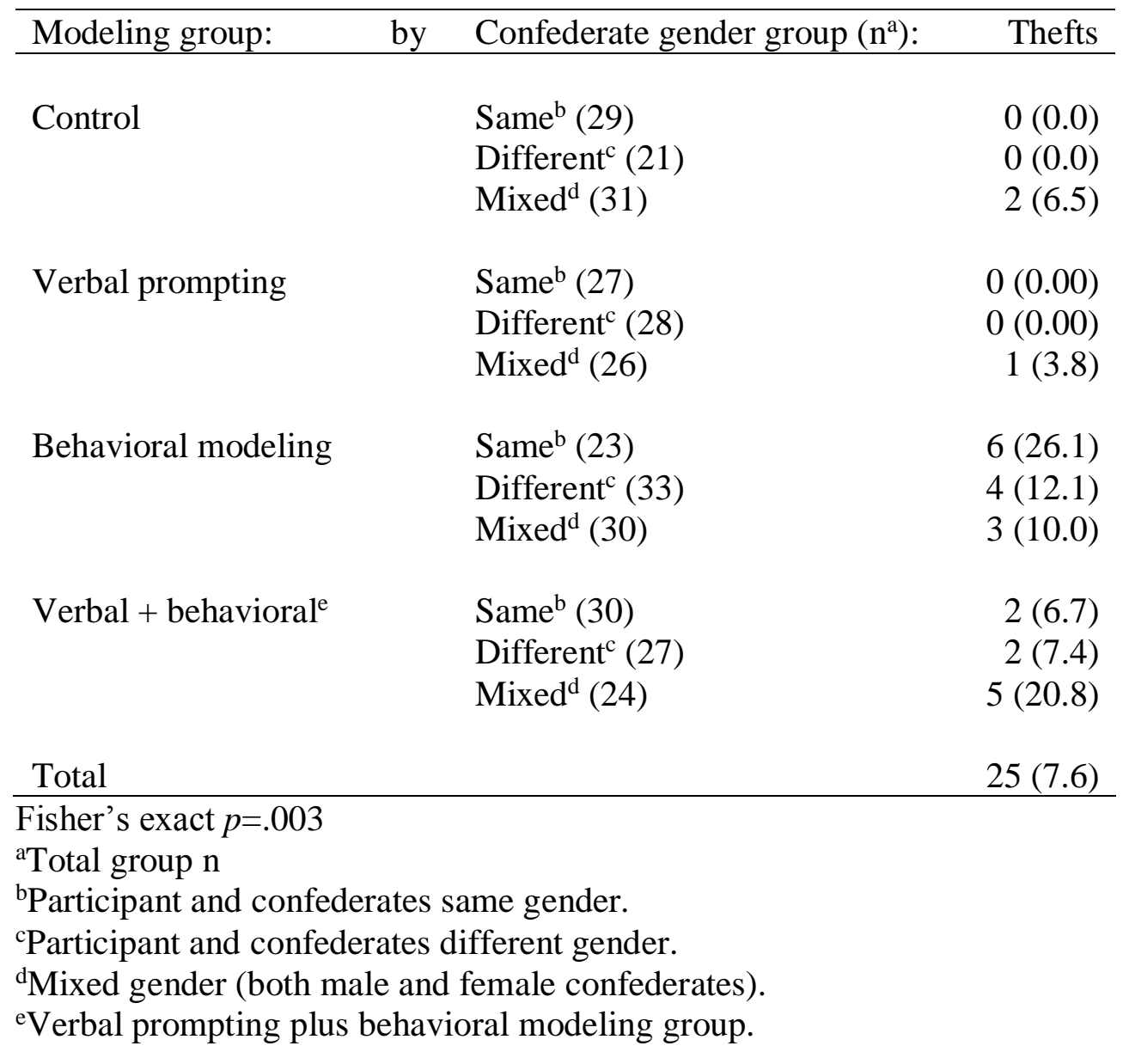


Supplementary online tables.

Table S1. Risk differences in theft by peer modeling group - difference (95\% CI)

\begin{tabular}{|c|c|c|c|}
\hline & $(0)$ & $(1)$ & (2) \\
\hline \multicolumn{4}{|l|}{ (0) Control } \\
\hline (1) Verbal prompting & $\begin{array}{c}-1.2 \\
(-5.4-2.9)\end{array}$ & & \\
\hline (2) Behavioral modeling & $\begin{array}{c}12.6 \\
(4.4-20.9)\end{array}$ & $\begin{array}{c}13.9 \\
(5.9-21.8)\end{array}$ & \\
\hline (3) Verbal + behavioral ${ }^{a}$ & $\begin{array}{c}8.6 \\
(1.0-16.3)\end{array}$ & $\begin{array}{c}9.9 \\
(2.6-17.1)\end{array}$ & $\begin{array}{c}-4.0 \\
(-14.2-6.2)\end{array}$ \\
\hline
\end{tabular}

${ }^{a}$ Verbal prompting plus behavioral modeling group. 
Table S2. Risk differences in theft by gender similarity group - difference (95\% CI)

\begin{tabular}{lcc}
\hline & $(0)$ & $(1)$ \\
\hline (0) Same $^{\mathrm{a}}$ & & \\
(1) Different $^{\mathrm{b}}$ & -1.8 & \\
& $(-8.3-4.7)$ & \\
& 2.6 & 4.4 \\
(2) Mixed $^{\mathrm{c}}$ & $(-4.8-10.0)$ & $(-2.6-11.4)$ \\
\hline
\end{tabular}

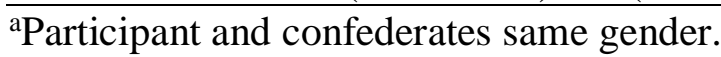

bParticipant and confederates different gender.

${ }^{\mathrm{c}}$ Mixed gender (both male and female confederates). 
Table S3. Risk differences in theft by interaction between peer modeling and gender similarity difference $(95 \% \mathrm{CI})$

\begin{tabular}{|c|c|c|c|c|c|c|}
\hline & $(0)$ & (1) & (2) & (3) & (4) & (5) \\
\hline $\begin{array}{l}\text { (0) Con/Same } \\
\text { (1) Con/Diff }\end{array}$ & $\begin{array}{c}0 \\
(-)\end{array}$ & & & & & \\
\hline (2) Con/Mixed & $\begin{array}{c}6.5 \\
(-2.2-15.1)\end{array}$ & $\begin{array}{c}6.5 \\
(-2.2-15.1)\end{array}$ & & & & \\
\hline (3) Verb/Same & $\begin{array}{c}0 \\
(-)\end{array}$ & $\begin{array}{c}0 \\
(-)\end{array}$ & $\begin{array}{c}-6.5 \\
(-15.1-2.2)\end{array}$ & & & \\
\hline (4) Verb/Diff & $\begin{array}{l}0 \\
(-)\end{array}$ & $\begin{array}{c}0 \\
(-)\end{array}$ & $\begin{array}{c}-6.5 \\
(-15.1-2.2)\end{array}$ & $\begin{array}{c}0 \\
(-)\end{array}$ & & \\
\hline (5) Verb/Mixed & $\begin{array}{c}3.8 \\
(-3.5-11.2)\end{array}$ & $\begin{array}{c}3.8 \\
(-3.5-11.2)\end{array}$ & $\begin{array}{c}-2.6 \\
(-14.0-8.8)\end{array}$ & $\begin{array}{c}3.8 \\
(-3.5-11.2)\end{array}$ & $\begin{array}{c}3.8 \\
(-3.5-11.2)\end{array}$ & \\
\hline (6) Behav /Same & $\begin{array}{c}26.1 \\
(8.1-44.0)\end{array}$ & $\begin{array}{c}26.1 \\
(8.1-44.0)\end{array}$ & $\begin{array}{c}19.6 \\
(-0.3-39.6)\end{array}$ & $\begin{array}{c}26.1 \\
(8.1-44.0)\end{array}$ & $\begin{array}{c}26.1 \\
(8.1-44.0)\end{array}$ & $\begin{array}{c}22.2 \\
(2.8-41.6)\end{array}$ \\
\hline (7) Behav /Diff & $\begin{array}{c}12.1 \\
(1.0-23.3)\end{array}$ & $\begin{array}{c}12.1 \\
(1.0-23.3)\end{array}$ & $\begin{array}{c}5.7 \\
(-8.4-19.8)\end{array}$ & $\begin{array}{c}12.1 \\
(1.0-23.3)\end{array}$ & $\begin{array}{c}12.1 \\
(1.0-23.3)\end{array}$ & $\begin{array}{c}8.3 \\
(-5.1-21.6)\end{array}$ \\
\hline (8) Behav /Mixed & $\begin{array}{c}10.0 \\
(-0.7-20.7)\end{array}$ & $\begin{array}{c}10.0 \\
(-0.7-20.7)\end{array}$ & $\begin{array}{c}3.5 \\
(-10.2-17.3)\end{array}$ & $\begin{array}{c}10.0 \\
(-0.7-20.7)\end{array}$ & $\begin{array}{c}10.0 \\
(-0.7-20.7)\end{array}$ & $\begin{array}{c}6.2 \\
(-6.9-19.2)\end{array}$ \\
\hline (9) $V+B /$ Same & $\begin{array}{c}6.7 \\
(-2.3-15.6)\end{array}$ & $\begin{array}{c}6.7 \\
(-2.3-15.6)\end{array}$ & $\begin{array}{c}0.2 \\
(-12.2-12.6)\end{array}$ & $\begin{array}{c}6.7 \\
(-2.3-15.6)\end{array}$ & $\begin{array}{c}6.7 \\
(-2.3-15.6)\end{array}$ & $\begin{array}{c}2.8 \\
(-8.8-14.4)\end{array}$ \\
\hline (10) $V+B / D i f f$ & $\begin{array}{c}7.4 \\
(-2.5-17.3)\end{array}$ & $\begin{array}{c}7.4 \\
(-2.5-17.3)\end{array}$ & $\begin{array}{c}1.0 \\
(-12.2-14.1)\end{array}$ & $\begin{array}{c}7.4 \\
(-2.5-17.3)\end{array}$ & $\begin{array}{c}7.4 \\
(-2.5-17.3)\end{array}$ & $\begin{array}{c}3.6 \\
(-8.8-15.9)\end{array}$ \\
\hline (11) V+B /Mixed & $\begin{array}{c}20.8 \\
(4.6-37.1)\end{array}$ & $\begin{array}{c}20.8 \\
(4.6-37.1)\end{array}$ & $\begin{array}{c}14.4 \\
(-4.0-32.8)\end{array}$ & $\begin{array}{c}20.8 \\
(4.6-37.1)\end{array}$ & $\begin{array}{c}20.8 \\
(4.6-37.1)\end{array}$ & $\begin{array}{c}17.0 \\
(-0.9-34.8)\end{array}$ \\
\hline
\end{tabular}

Table S3, continued.

\begin{tabular}{|c|c|c|c|c|c|}
\hline \multirow{2}{*}{\multicolumn{6}{|c|}{ (6) Behav /Same }} \\
\hline & & & & & \\
\hline (7) Behav /Diff & $\begin{array}{c}-14.0 \\
(-35.1-7.2)\end{array}$ & & & & \\
\hline (8) Behav/Mixed & $\begin{array}{c}-16.1 \\
(-37.0-4.8)\end{array}$ & $\begin{array}{c}-2.1 \\
(-17.6-13.3)\end{array}$ & & & \\
\hline (9) $V+B /$ Same & $\begin{array}{c}-19.4 \\
(-39.5-0.6)\end{array}$ & $\begin{array}{c}-5.5 \\
(-19.7-8.8)\end{array}$ & $\begin{array}{c}-3.3 \\
(-17.3-10.6)\end{array}$ & & \\
\hline (10) $V+B / D i f f$ & $\begin{array}{c}-18.7 \\
(-39.2-1.8)\end{array}$ & $\begin{array}{c}-4.7 \\
(-19.6-10.2)\end{array}$ & $\begin{array}{c}-2.6 \\
(-17.2-12.0)\end{array}$ & $\begin{array}{c}0.7 \\
(-12.6-14.1)\end{array}$ & \\
\hline (11) V+B /Mixed & $\begin{array}{c}-5.3 \\
(-29.5-19.0)\end{array}$ & $\begin{array}{c}8.7 \\
(-11.0-28.4)\end{array}$ & $\begin{array}{c}10.8 \\
(-8.6-30.3)\end{array}$ & $\begin{array}{c}14.2 \\
(-4.4-32.7)\end{array}$ & $\begin{array}{c}13.4 \\
(-5.6-32.4)\end{array}$ \\
\hline
\end{tabular}

Con $=$ control

Verb $=$ verbal prompting

Behav = behavioral modeling

$\mathrm{V}+\mathrm{B}=$ verbal prompting plus behavioral modeling

Same $=$ participant and confederates same gender

Diff $=$ participant and confederates different gender

Mixed $=$ mixed gender (both male and female confederates) 